\title{
Towards a New Geoid Model of Tanzania Using Precise Gravity Data
}

\author{
Selassie David Mayunga \\ School of Geospatial Sciences and Technology, Ardhi University, Dar Es Salaam 35176, Tanzania
}

\begin{abstract}
The new geoid model of Tanzania is a major breakthrough in the determination of vertical heights for the past 60 years. A new geoid model has been computed using precise gravity data supplemented with marine gravity data from Gravity Recovery and Climate Experiment (GRACE) satellite and new high-resolution satellite gravity data from Gravity field and steady-state Ocean Circulation Explorer (GOCE). A digital terrain model was also used based on 15" Shuttle and Rader Terrain Model (SRTM) data. The use of gravity data makes an orthometric height easily computed using Global Navigation Satellite System (GNSS). The GNSS is being used in many African countries including Tanzania and soon it will replace conventional leveling technique and avoid frequent maintenance of benchmarks. This paper presents preliminary result of a new geoid model which shows that by using precious gravity data and Remove-Compute-Restore technique, an accuracy of $10 \mathrm{~cm}$ can be reached.
\end{abstract}

Key words: Old vertical datum, new geoid datum, Global Navigation Satellite System.

\section{Introduction}

Tanzania Leveling Network (TLN) was designed in 1960 and implemented between 1961 and 1964. It comprised 53 Fundamental Benchmarks (FBM) based on local Mean Sea Level (MSL). The FBM were established by seven level roots. However, they are not homogenous. At the same time, they have never been validated since establishment. In view of limitations of the existing vertical network along with the growing demand of a precise geoidal model, Tanzania embarked on the establishment of a new geoid datum using precise aerial gravity data. The determination of a new vertical reference frame was implemented by the government of Tanzania in collaboration with the National Space Institute, Technical University of Denmark and the National Geospatial-Intelligence Agency of the United States of America funded by the World Bank. The main advantage of using precise gravity data is on computation of the gravity anomalies. Gravity anomalies being the difference between that the observed acceleration due to gravity

Corresponding author: Selassie David Mayunga, master, research fields: geodesy and geomatics engineering. at the earth's surface was used to compute geoid and orthometric heights. A geoid is an imaginary surface of global mean sea level used to measure precise surface elevations. The term geoid as defined by Vaníček, P. and Kleusberg, A. [1] includes the determination of the gravity field of the earth in a three dimensional space.

\subsection{Related Works/Previous Works}

For more than two decades, various attempts have been reported on the determination of vertical reference frames as a way of utilizing global positioning systems. Sylvester, B. [2] developed a technique of computing point values of a gravimetric geoid using short wavelength. The gravimetric values obtained were tested using Doppler derived values, Sea Satellite (SEASAT) altimetry and Rapp's using $180^{\circ}$ by $180^{\circ}$ solutions. However, it was later recommended that to obtain the utmost accuracy of the gravimetric solution, it was important to apply corrections for the atmospheric attraction, topographic effect and their indirect effects. Also Sylvester, B. [2] developed a three space Stokes-Helmert scheme to determine geoid using precise gravimetric data. The final geoid was compared 
with GPS/Leveling whereby differences were recorded due to long wavelength and bias between the geometric and gravimetric geoid models. Ulotu, P. [3] developed a procedure to create a Gravity Database (GDB) using sparse gravity data with varying density, distribution and quality. A spherical harmonic expansion of the Earth's geo-potential derived from the GRACE satellite mission was used to model the long wavelength component of the geoid. However, even after using KHT method and Least Squares Modification of Stokes to compute geoid of Tanzania, the accuracy obtained was $29.7 \mathrm{~cm}$.

Richard, W. and Charles, M. [4] improved the South African Vertical Geoid Model (SAGEOID2010) using global EGM2008 combined with Gravity field and steady-state Ocean Circulation Explorer (GOCE) satellite data. Merry, C. L. [5] used a spherical harmonic expansion of the Earth's geo-potential derived from the GRACE satellite to model the long wavelength component of the geoid model. The residuals of the geoid model were determined from a combination of land and marine gravity anomalies and a digital elevation model. Despite of all these attempts, the availability of precise gravity data remained a big challenge for geoid determination.

In 2001, Africa countries through the International Association of Geodesy (IAG) initiated an ambitious project to determine Africa geoid [6]. The project was aimed at unifying vertical datum for Africa using data from African Reference Frame (AFREF). The Africa Geoid Project (AGP) was implemented based on assumption that some of the controls points were established using Global Positioning Systems (GPS). The Africa geoid model (AGP2003) was computed but never validated due to insufficient GPS/leveling data from which the geoidal height could be deduced. Very few GPS data were determined in Algeria, Egypt and South Africa and biases were found due to different vertical datums used. It is important to note that, the reference frame for GPS is the WGS84, whereby heights are determined with reference to the WGS84 ellipsoid.

For GPS-derived heights being referred to an appropriate surface, the geoidal height must be known. A geoidal height can be precise determined by using gravity data. Practically, gravity data coverage over Africa is a long way short as there are large gaps of gravity data causing the determination of a unified geoid model of African being difficult. Therefore, for a unified geoid model for Africa to be realized, there is a need to fill in these gaps, possibly by using airborne gravimetry. Therefore, in order to attain a higher accuracy of a unified geoid model for Africa, a uniform gravity data is required.

Tanzania like other African countries uses conventional leveling network based on Mean Sea Level (MSL) defined through a series of FBMs and tide gauges. This vertical network is not homogenous particularly with neighbouring countries causing gaps in height measurements along borders. However, modern vertical reference frames are homogeneous and based on a well defined geoid which can easily be validated using well defined procedures. The determination of height using conventional leveling technique is expensive, time consuming and tedious as some benchmarks are destroyed and difficult to locate. With the increased use of GPS to determine controls, there is an urgent need to replace the conventional leveling techniques with the new geoid models.

Having realized the urgent need for a new vertical datum and the failure of African Geoid Project, the government of Tanzania with assistance from the World Bank initiated an ambitious project to determine a new geoid model. This ambitious project is a breakthrough for determination of vertical datum in Tanzania for the past 60 years. The determination of a new vertical datum is aimed at replacing the conventional Leveling Network and creates an environment for effective use of GPS.

\subsection{Planning and Gravity Data Acquisition}

Gravity measurement on the surface of the earth is 
an expensive exercise and time consuming. Gravity measurement in this project was carried out using gravity lines as shown in Fig. 1. The Fig. 1 shows the gravity lines covering an area of the United Republic of Tanzania. The observations show that the gravity observed in June 2012 blends seamlessly with the gravity observed in October 2013 as shown in Fig. 2. The combined gravity data set forms the basis for the computation of the Tanzanian geoid as described in section 2 .

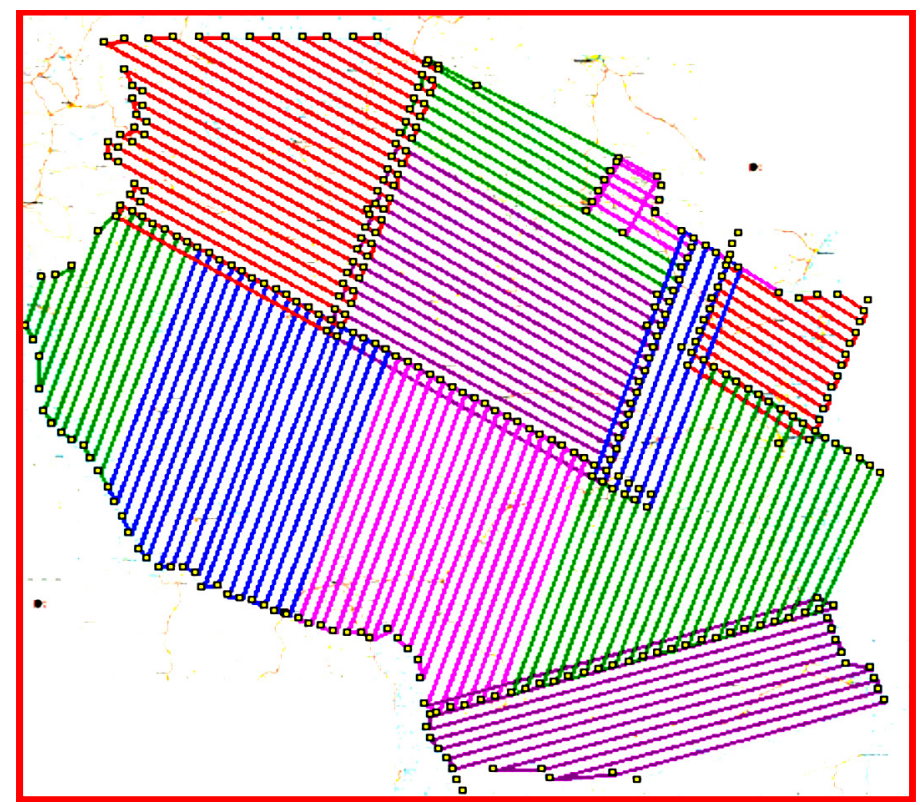

Fig. 1 Flight lines covering Tanzania.

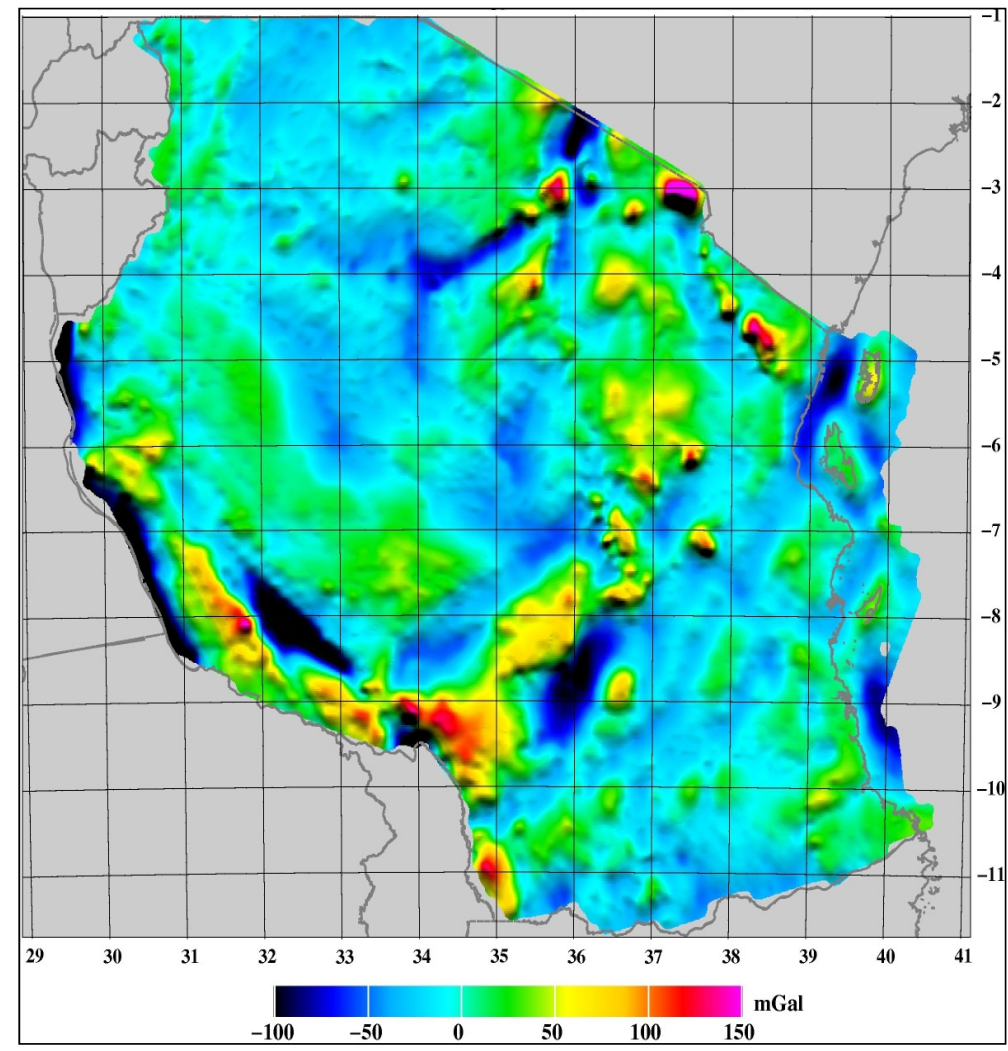

Fig. 2 Gridded free air anomalies for gravity data observed from June 2012 to October 2013. 


\section{Materials and Methods}

\subsection{Gravity Data Processing}

One of the challenges in geoid determination is the availability of topographic density variation which is usually not known. Recent research on determination of topographic density variation shows that Helmet second condensation method combined with Stokes can generate the required topographic density at the same time improve the accuracy of the geoid model [7]. Also, it was further stated that the accuracy of the geoid model can be improved to a centimeter level if the observations and processing techniques of gravity data are improved.

Based on the recommendations made by Gruen, A. [8], the Tanzania geoid was computed using Gravity Field Modeling software developed by DTU-Space, Niels Bohr Institute and University of Copenhagen. Gravsoft software has been used to compute geoid in Nordic and Baltic countries, United Kingdom and Ireland, Mongolia, Malaysia and Indonesia. The geoid model was computed using gravity data measured between 2010 and 2013, airborne gravity survey data, marine gravity data from GRACE satellite data (EGM08) and high-resolution satellite gravity from GOCE mission. Also, a digital terrain model was used in the computation process based on 15" SRTM data using Remove-Compute-Restore technique where a spherical harmonic of Earth Geopotential Model (EGM) was treated as a base. The computation of the geoid was carried out from global geopotential model $\mathrm{N}_{\text {EGM }}$, a local gravity derived components $N_{2}$, and a terrain part $N_{3}$ is described as in Eq. (1):

$$
N_{\text {grav }}=N_{E G M}+N_{2}+N_{3}
$$

Eq. (1) is the computation of gravimetric geoid. The spherical harmonic is expressed as a function of latitude, longitude and height as in Eq. (2):

$$
\begin{aligned}
N(\emptyset, \lambda, r) & =\frac{G M}{R^{\prime} \gamma}\left(\frac{\mathrm{R}}{\mathrm{r}}\right) \sum_{\mathrm{m}=0}^{\mathrm{n}}\left(\mathrm{c}_{\mathrm{nm}} \cos \mathrm{m} \lambda\right. \\
& \left.+\mathrm{s}_{\mathrm{nm}} \sin \mathrm{m} \lambda\right) \mathrm{P}(\sin \emptyset)
\end{aligned}
$$

Eq. (2) is the spherical harmonic function.

Where, GM, $\mathrm{R}$ and $\lambda$ are earth parameters. The combined EGM08 and GOCE models (EGM/GOCE) used $\mathrm{Cnm}$ and Snm coefficients derived from a large set of global satellite data and regional gravity data. In this project, the combined spherical harmonic models (EGM08/GOCE) has been used to a spherical harmonic degree $\mathrm{N}=720$, which is equivalent to a resolution of 15 " or approximately $28 \mathrm{~km}$. The selection of these parameters was based on DTU experience in computing geoids of different countries.

The terrain computation was based on the Residual Terrain Model (RTM) where topography is referred to as mean sea level, and the only residuals relative to this level was taken into consideration. The mean elevation surface was derived from the SRTM at 15" through a moving average filter with a resolution of approximately $45 \mathrm{~km}$. The difference in resolution between reference gravity field and RTM was taken care using remove-compute-restore technique. The spherical Fourier Transform with optimized kernel was used to determine the gravimetric geoid which is mathematically expressed as in Eq. (3):

$$
\begin{gathered}
N_{2}=S_{\text {ref }}(\Delta \varphi ; \Delta \lambda) x\left[\Delta g_{2}(\varphi, \lambda) \sin \varphi\right]= \\
F^{-1}\left[F\left(S_{\text {ref }}\right) F(\Delta g \sin \varphi)\right]
\end{gathered}
$$

Eq. (3) computes local gravimetric geoid.

Where, $S_{r e f}$ is a modified "Stokes" kernel, $\Delta g_{2}$ is the combined EGM08/GOCE reduced free-air gravity anomaly and $F$ is the 2-dimensional Fast Fourier Transform operator (FFT). The computations have been based on least squares collocation and Fast Fourier Transformation methods. The FFT transformation at the $2 \mathrm{~km}$ resolution involved $1,400 \times 1,500$ gridded points, which corresponds to $100 \%$ zero padding. The data were gridded, downwarded and then continued by least squares collocation using the planar logarithmic model. Fig. 3a shows Tanzanian land gravity data used for the geoid computation after removing problematic surface gravity area in the South West region of the country. Fig. $3 b$ shows the airborne gravity data while Fig. $3 \mathrm{c}$ show the flight elevation. 


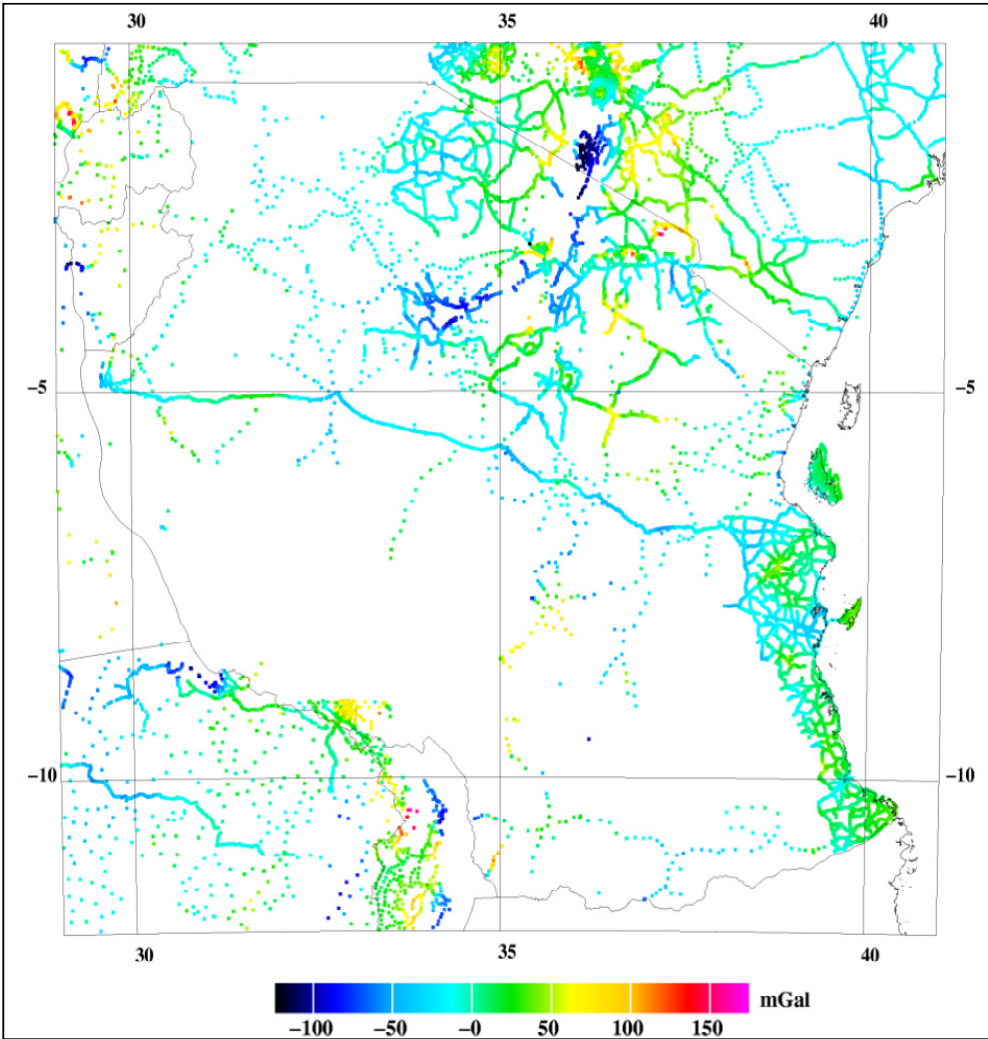

Fig. 3a Land gravity data (free-air anomalies).

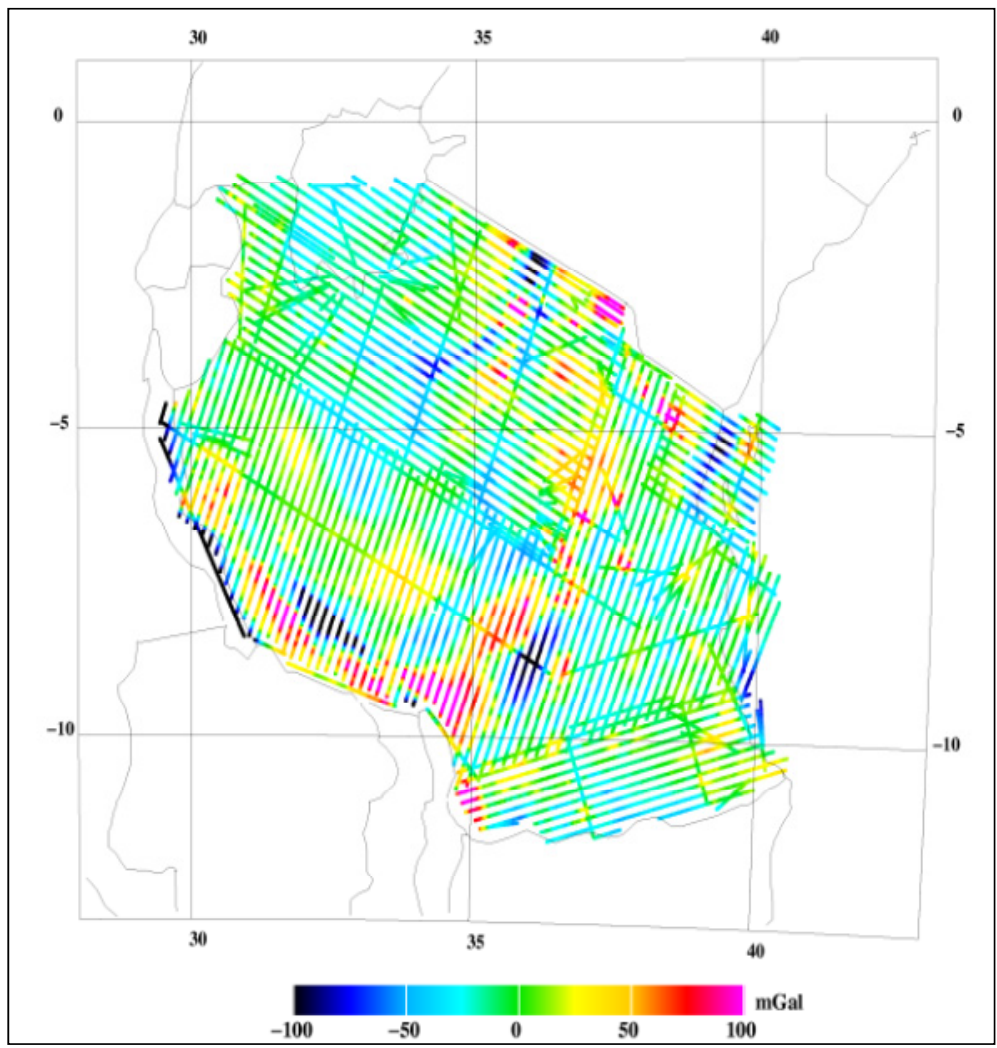

Fig. 3b Airborne gravity data (free-air anomalies). 


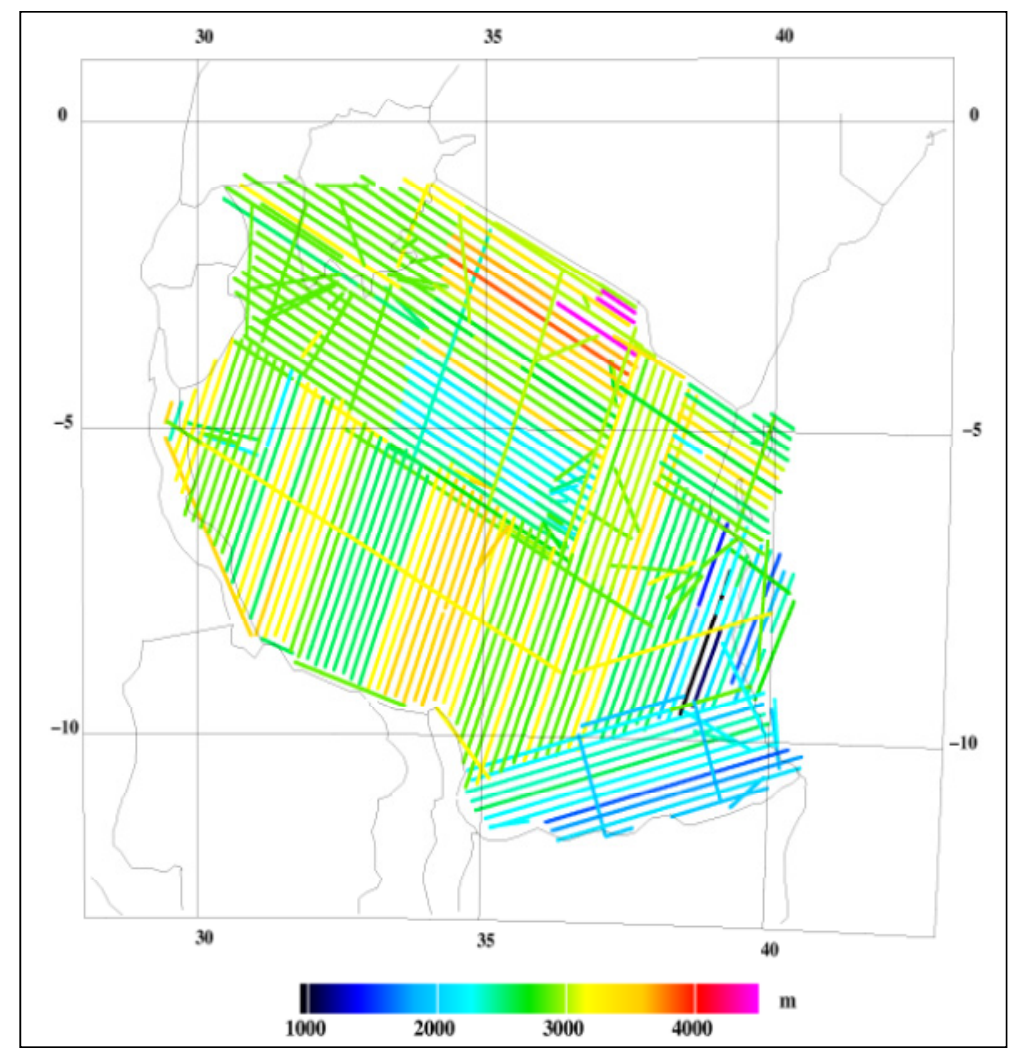

Fig. 3c Flight elevations.

Table 1 The statistics of the remove steps.

\begin{tabular}{lllll}
\hline Unit: mGal & Mean & Standard deviation & Min. & Max. \\
\hline Land gravity data & 4.4 & 36.0 & -125.5 & 256.1 \\
Land gravity minus EGM08GOCE and RTM & 3.2 & 13.8 & -109.3 & 164.3 \\
Airborne gravity data & -4.7 & 33.5 & -189.4 & 225.2 \\
Airborne minus EGM08GOCE and RTM & 0.6 & 12.0 & -98.0 & 85.0 \\
All gravity data minus EGM08GOCE and RTM & 1.5 & 10.8 & 102.2 & 166.1 \\
\hline
\end{tabular}

\section{Results and Discussion}

The final geoid of Tanzania covers the grid of $0.02^{\circ}$ $\times 0.02^{\circ}$ resolution which is about $(2 \times 2) \mathrm{km}$. The intermediate results were computed using remove-restore technique with three dimensional modeling via quasi-geoid to obtain the final geoid model. The final Tanzania geoid model is bounded with Latitude $13^{\circ} \mathrm{S}-1^{\circ} \mathrm{N}$ and $28^{\circ}-43^{\circ} \mathrm{E}$ with a resolution of $0.02^{\circ}$. A priori error was assumed to be 2 $\mathrm{mGal}$ for the airborne data and $1 \mathrm{mGal}$ for the surface data. Fig. 4 shows the downward continued reduced gravity data from the least squares computation.
For the spherical FFT transformation of gravity to the geoid, 3 reference bands with grid dimensions of $560 \times 600$ points for gravity and $1,400 \times 1,500$ points for the terrain were used which corresponds to $100 \%$ zero padding. Figs. 5-7 show the results of reduced geoid.

Fig. 8 shows the final geoid model of Tanzania while Fig. 9 shows The Tanzanian geoid (TGD2013) with $2 \mathrm{~m}$ Contour interval. The final geoid is provided for with a GRAVSOFT grid that can be used to interpolate any point on the surface using developed Graphical User Interface (GUI). 


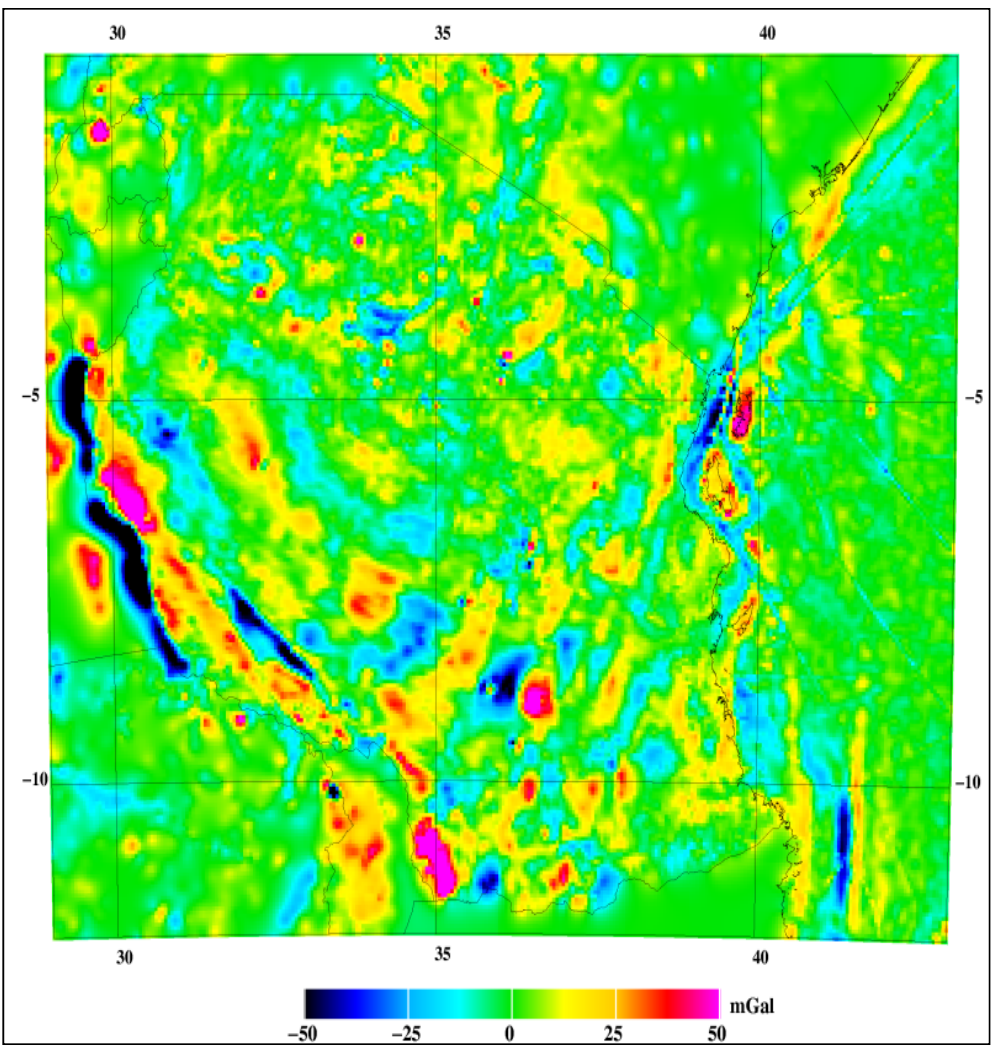

Fig. 4 Downward continued reduced gravity data.

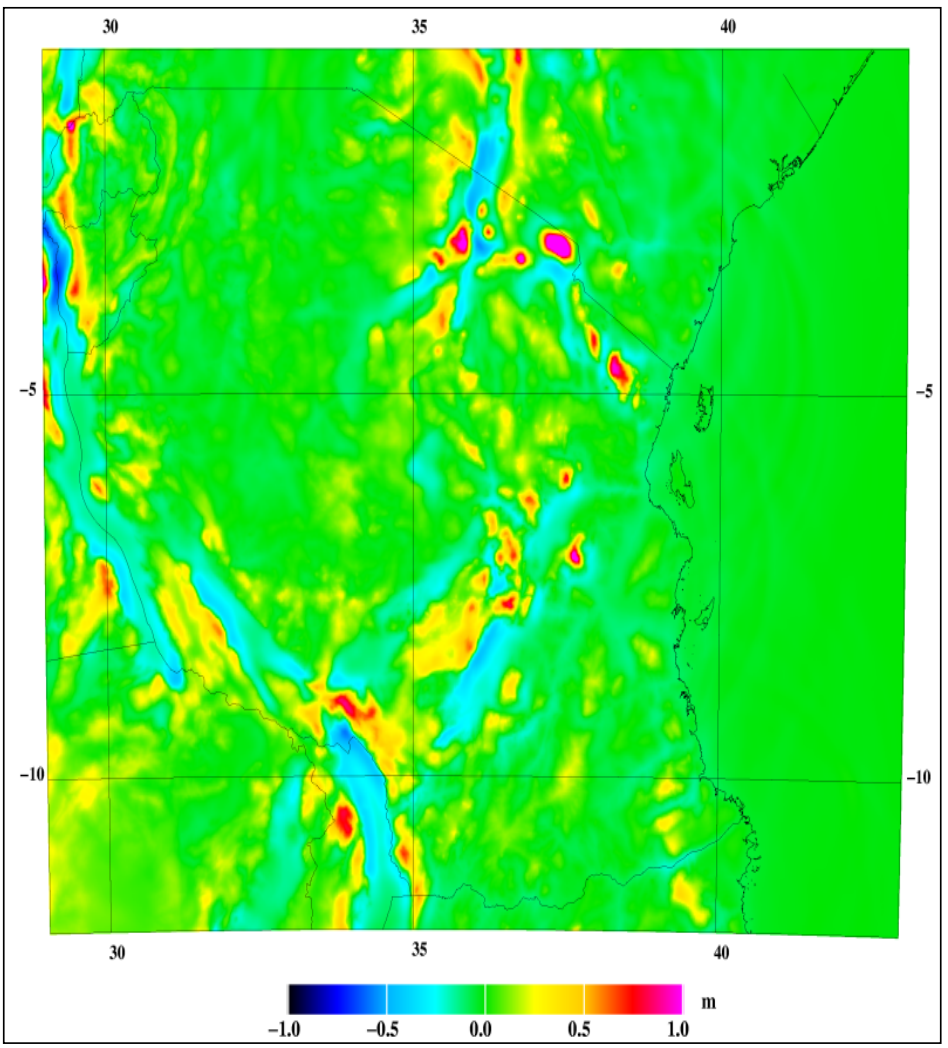

Fig. 5 Reduced geoid after spherica FFT transformation. 


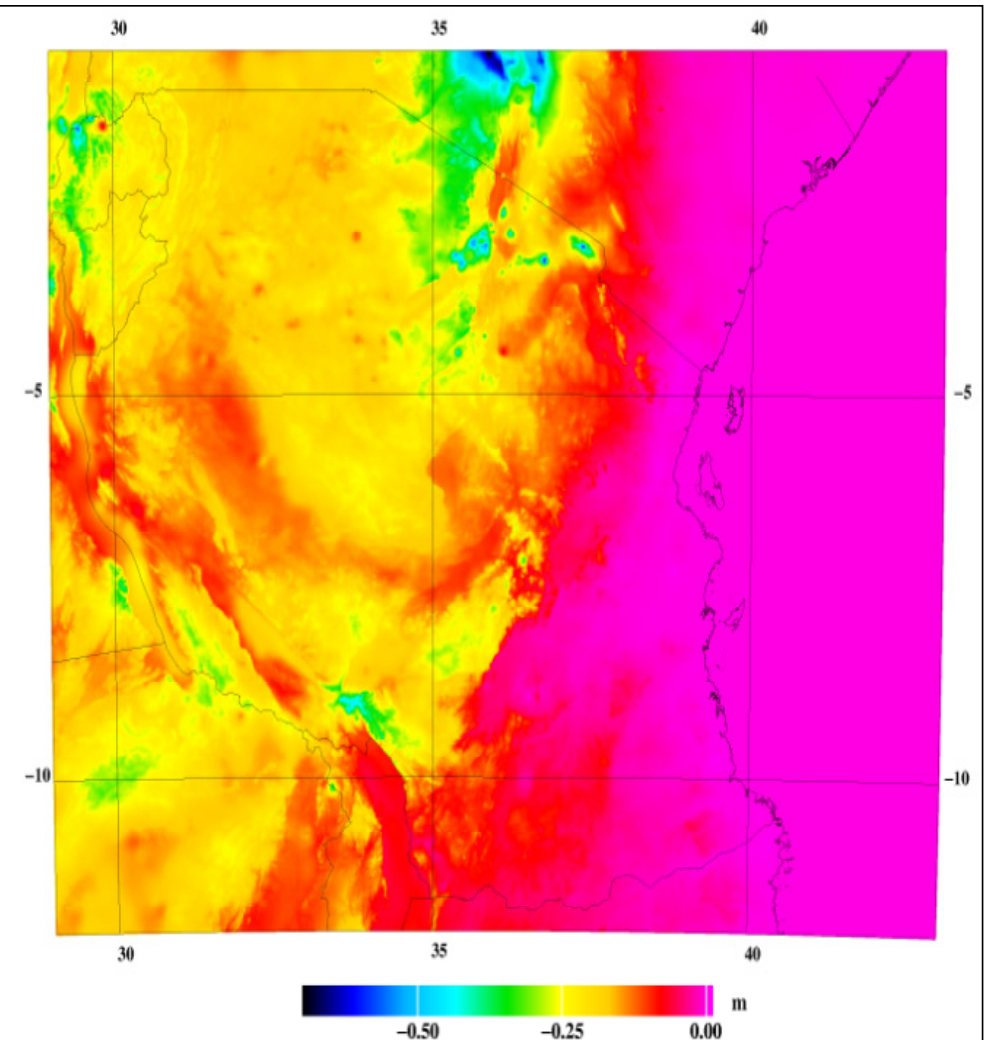

Fig. 6 Correction applied to obtain classical geoid.

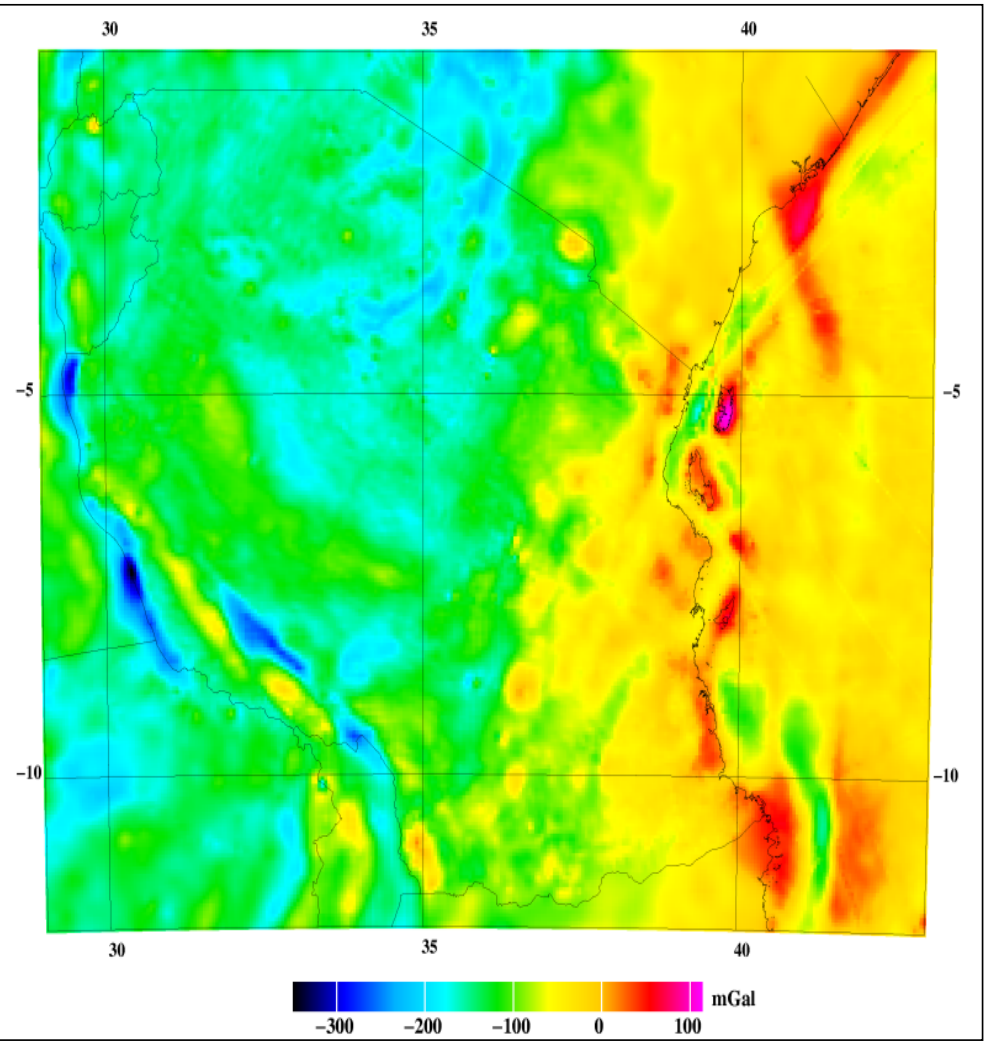

Fig. 7 Bouguer anomaly grid, derived from the geoid used for the geoid-quasi-geoid estimation. 


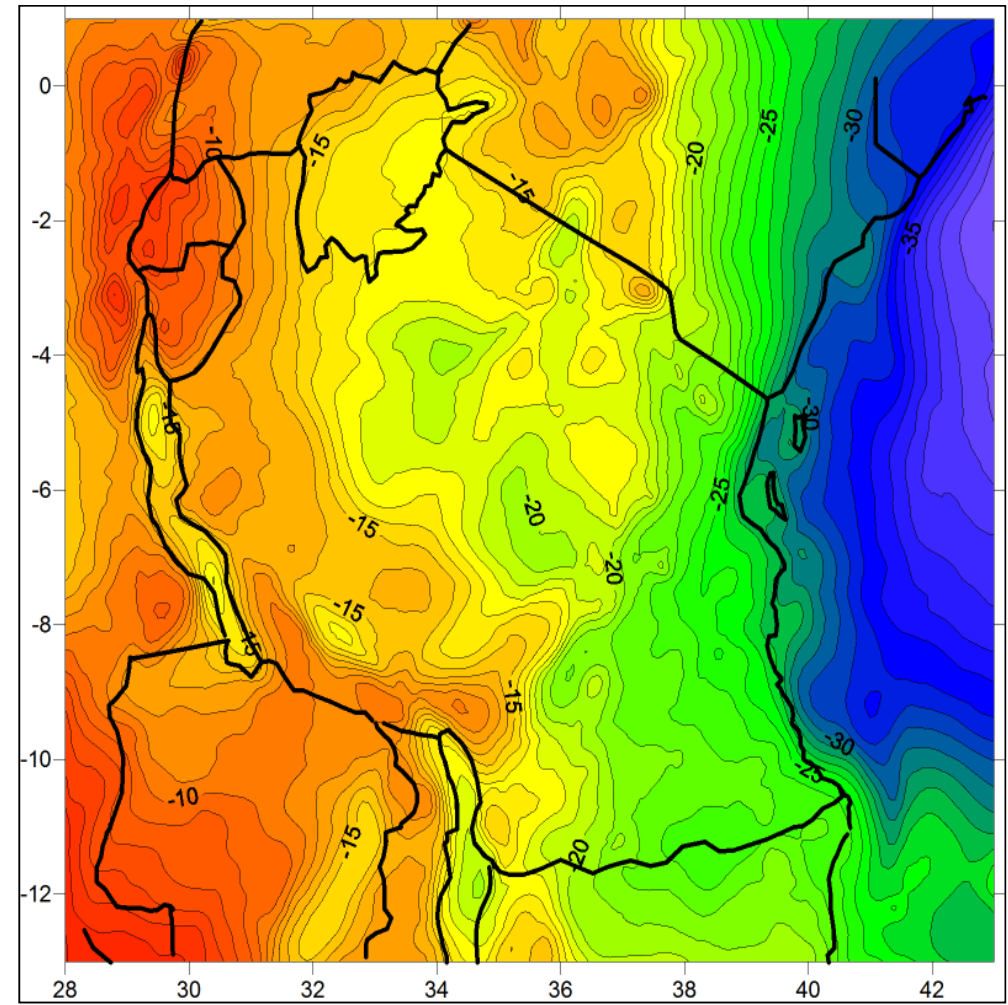

Fig. 8 Final Geoid of Tanzania (TGD2013).

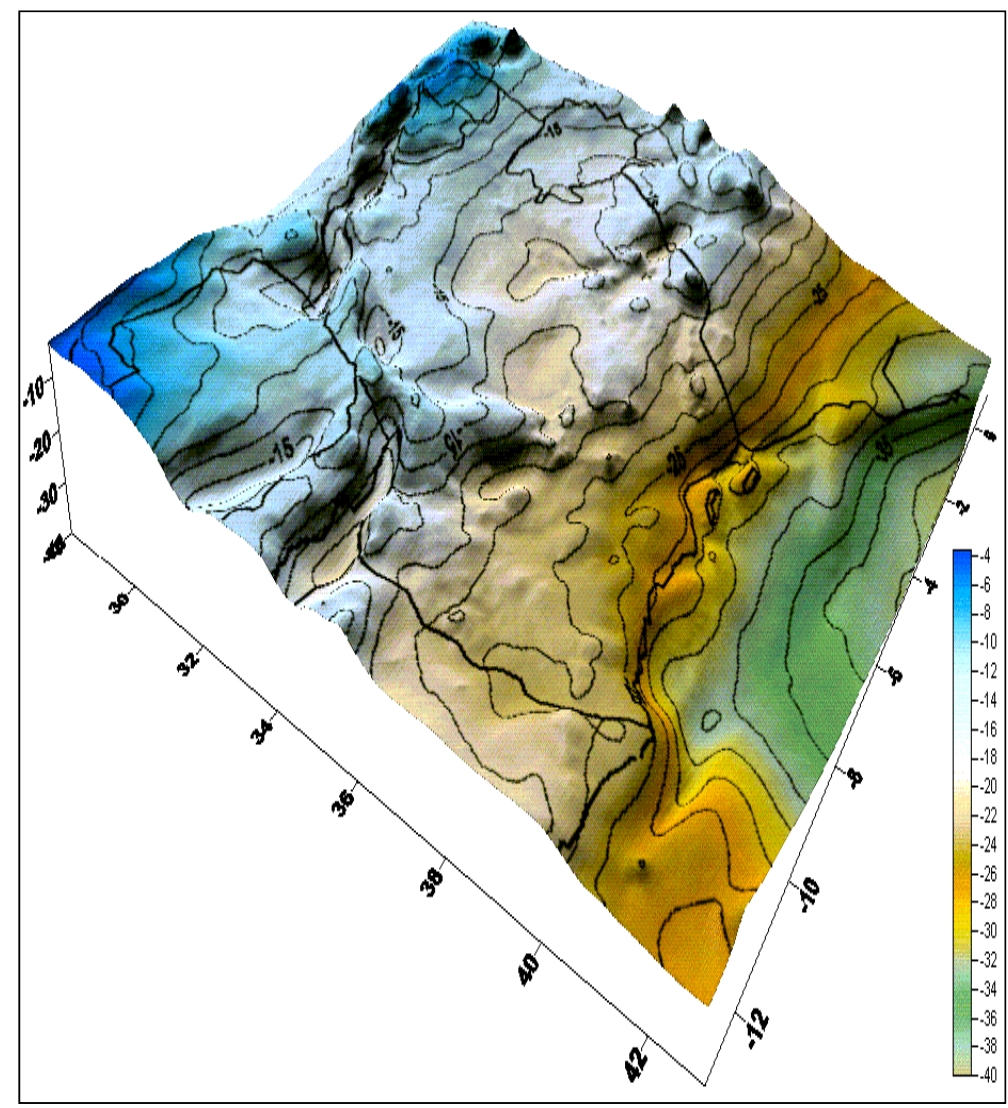

Fig. 9 Tanzania new Geoid Datum with 2 m contour interval. 


\section{Conclusions}

This paper presents preliminary results of a new geoid model of Tanzania computed using precious gravity data using GRASOFT software developed by DTU-Space, Niels Bohr Institute and University of Copenhagen. The new geoid model will replace the old conventional vertical leveling network to pave way for utilizing Global Navigation Satellite Systems (GNSS) for determination of three dimensional positions. The geoid model was successfully computed using precise gravity data supplemented with marine gravity data from GRACE satellite and new high-resolution Gravity field and steady-state Ocean Circulation Explorer (GOCE) satellite. Also, a digital terrain model was used based on 15" SRTM data. The accuracy of a new geoid model is $10 \mathrm{~cm}$. However, validation of the new geoid model is currently taking place before it can be effectively used by the public.

\section{References}

[1] Vaníček, P., and Kleusberg, A. 1987. The Canadian
Geoid. University of New Brunswick Technical report.

[2] Sylvester, B. 2013. "Establishing a Geodetic Reference Network in Montserrado County_Liberia, Using GNSS Technology." Master thesis, Kwame Nkrumah University of Science and Technology.

[3] Ulotu, P. 2009. "Geoid Model of Tanzania from Sparse and Varying Gravity Data Density by the KTH Method." Ph.D. thesis, Royal Institute of Technology (KTH).

[4] Richard, W., and Charles, M. 2010. "A New Vertical Datum for South Africa” In SAGEOID, Position IT, 29-33

[5] Merry, C. L. 2001. "The African Geoid Project and Its Relevance to the Unification of African." Vertical Reference Frames. Accessed January 18, 2016. https://www.fig.net/.../fig.../TS9_3_merry.pdf.

[6] Merry, C. L. 2007. "Tan Updated Geoid Model for Africa Presented at XXIV General Assemble of the International Union of Geodesy and Geophysics, Perugia.” Accessed January 18 , 2016 http://www.iugg2007perugia.It/abstractdetails.asp.

[7] Vaníček, P., and Ellmannet, A. 2013. "UNB Application of Stokes-Helmert's Approach to Geoid Computation.” Journal of Geodynamics 43: 200-213.

[8] Gruen, A., 2000. "Potential and Limitation of High-resolution Satellite Imagery.” Presented at Keynote Address, 21st Asian Conference on Remote Sensing. 